\title{
"The unpredictable death"-The last year of life for patients with advanced COPD: Relatives' stories
}

\author{
KRISTINA EK, R.N., PH.D., ${ }^{1}$ BIRGITTA ANDERSHED, R.N.T., PH.D., ${ }^{2,3}$ \\ EVA SAHLBERG-BLOM, R.N., PH.D., ${ }^{4}$ AND BRITT-MARIE TERNESTEDT, R.N.T., PH.D. ${ }^{2,5}$ \\ ${ }^{1}$ School of Health and Education, University of Skövde, Skövde, Sweden \\ ${ }^{2}$ Department of Palliative Care Research, Ersta Sköndal University College, Stockholm, Sweden \\ ${ }^{3}$ Department of Nursing, Gjøvik University College, Gjøvik, Norway \\ ${ }^{4}$ School of Health and Medical Sciences, Örebro University, Örebro, Sweden \\ ${ }^{5}$ Department of Neurobiology, Care Sciences and Society, Karolinska Institutet, Stockholm, Sweden \\ (RECEIVED July 17, 2014; ACCEPTEd August 27, 2014)
}

\begin{abstract}
Objective: The end stage of chronic obstructive pulmonary disease (COPD) is described as prolonged, and the symptom burden for patients with COPD is often high. It progresses slowly over several years and can be punctuated by abrupt exacerbations that sometimes end in sudden death or a recovery of longer or shorter duration. This makes it difficult to identify the critical junctures in order to prognosticate the progress and time of death. Patients with COPD often express a fear that the dying process is going to be difficult. There is a fear that the dyspnea will worsen and lead to death by suffocation. The present article aimed to retrospectively describe the final year of life for patients with advanced COPD with a focus on death and dying from the perspective of relatives.

Method: Interviews were conducted with the relatives of deceased family members who had advanced COPD. In total, 13 interviews were conducted and analyzed by means of content analysis.

Result: All relatives described the patients as having had a peaceful death that did not correspond with the worry expressed earlier by both the patients and themselves. During the final week of life, two different patterns in the progress of the illness trajectory emerged: a temporary improvement where death was unexpected and a continued deterioration where death was inevitable.

Significance of Results: The patients and their relatives lived with uncertainty up until the time of death. Little support for psychosocial and existential needs was available. It is essential for the nurse to create relationships with patients and relatives that enable them to talk about dying and death on their own terms.
\end{abstract}

KEYWORDS: Chronic obstructive pulmonary disease, End of life, Palliative care, Oxygen therapy, Dying and death

\section{INTRODUCTION}

Advanced chronic obstructive pulmonary disease (COPD) is a progressive disease with no known cure and is one of the five principal causes of mortality in the world (World Health Organization, 2007).

Address correspondence and reprint requests to: Kristina Ek, University of Skövde, The School of Health and Education, Box 408, SE-541 28 Skövde, Sweden. E-Mail: kristina.ek@his.se
The end-of-life phase and death are certainly very important events in our lives (Seymour \& Ingleton, 2004), and it is known that this period requires special attention when it comes to patients who suffer with COPD. These patients do not usually have access to palliative care the way that people with, for example, cancer diagnoses have (Curtis et al., 2002), which may result in inadequate care with respect to their needs (Au et al., 2006; Elkington et al., 2005). It is also known that relatives often do not receive 
the support they need during different phases of the disease (Ek et al., 2011a; 2011b). This affects the wellbeing and daily quality of life of all family members. The symptom burden for patients with COPD is high, involving breathlessness, coughing, phlegm, fatigue, dejection (Lowey et al., 2013; Gullick \& Stainton 2008; Elkington et al., 2005; Seamark et al., 2004; Edmonds et al., 2001; Claessens et al., 2000), anxiety, and depression (Wagena et al., 2005; Shackell et al., 2007; van Manen et al., 2002). Due to the severe symptoms, a patient's health situation is described as poor (Habraken et al., 2009; Ek \& Ternestedt, 2008; Fraser et al., 2006; Barnett, 2005; Jones et al., 2004). However, some studies have shown that many patients are able to create a life that also contains meaningfulness despite their difficulties (Ek et al., 2011a; 2011b; Ek \& Ternestedt, 2008). The existential suffering is often described in feelings of guilt and meaninglessness (Ek \& Ternestedt, 2008; Reinke et al., 2008). Depression and anxiety are often major problems close to death (Lynn et al., 2000). However, these problems often go unnoticed by health professionals (Strang et al., 2013; Spence et al., 2009; Maurer et al., 2008). Fear of slowly suffocating to death is also often described (Ek et al., 2011a; 2011b; Gardiner et al., 2009; Habraken et al., 2007).

COPD is likely to progress slowly over several years and can be punctuated by sudden exacerbations that sometimes end in sudden death (Lunney et al., 2003; Rabe et al., 2007; Murray et al., 2005) or a recovery of longer or shorter duration. This makes it difficult to identify the critical junctures in order to prognosticate about disease progress and time of death (Gott et al., 2009; Spence et al., 2009). The end stage of COPD is described as prolonged (Habraken et al., 2009), although there are variations. Patients with COPD often express a fear that the dying process is going to be difficult (Nguyen et al., 2013; Ek, 2010). There is, for example, a fear that the dyspnea will worsen and lead to death by suffocation (Hall et al., 2010; Ek et al., 2011b). Few studies have been published that describe the final time of life for patients with advanced COPD. Therefore, it seemed important to study the final year of life, including the care needs, with a particular focus on the last week of life-that is, on dying and death.

\section{AIM}

The aim of our study was to retrospectively describe the final year of life for patients with advanced COPD with a focus on dying and death from the perspective of relatives.

\section{METHODS}

The study had a descriptive design. The data were collected by interviews with relatives of deceased patients who had suffered from advanced COPD. The interviews were supplemented with descriptions of the course of the patients' disease, based on a time axis, constructed by the relatives. The data were analyzed using qualitative content analysis (Graneheim \& Lundman, 2004).

\section{Participants}

The study sample was suitable (see Patton, 2002). The relatives were recruited from a pulmonary clinic at a university hospital in central Sweden and identified from deceased patients' medical records. To be included in the study, the patients needed to have had COPD as the primary diagnosis and long-term oxygen therapy (LTOT) 16-24 hour per day. The criteria for inclusion of relatives were that the relative was named as the patient's next of kin in the medical records and was involved in the patient's final phase of life. An informational letter about the study was sent to 36 relatives (named in 36 records). Thereafter, the first author phoned the relatives, gave additional information about the study, and asked if they were interested in participating. In all, 10 relatives declined participation because they had not been involved in the patient's last phase of life, and 13 relatives did not state any reason for not participating. In total, 13 relatives (five husbands, four wives, two sons, and two daughters) agreed to participate. The interviews were conducted during 2009. The characteristics of the deceased patients are presented in Table 1.

\section{Ethical Considerations}

Information about the voluntary nature of the informants' participation and the right to withdraw was provided both before and during the interviews in verbal and written forms. Experience from interviews in similar situations has shown that people can reap benefits from talking over a difficult situation and that communicating about it can help them move along in the grieving process (cf. Werkander-Harstäde, 2012; Ek 2010; Melin-Johansson et al., 2008). Our study was approved by the regional ethics review board in Uppsala, Sweden (approval no. 2007/121).

\section{Data Collection}

\section{Interviews and Time Axis}

Retrospective interviews with relatives constitute a common method for collecting information about the 
Table 1. Characteristics of patients with advanced COPD

\begin{tabular}{|c|c|c|c|c|c|}
\hline Name & Age & Sex & Length of LTOT & Place of Death & Relatives \\
\hline $\mathrm{P} 1$ & 70 & Female & 2 years & Intensive care unit & Husband \\
\hline $\mathrm{P} 2$ & 70 & Female & 1,5 years & Pulmonary clinic & Child \\
\hline P3 & 75 & Male & 1 year & Pulmonary clinic & Wife \\
\hline $\mathrm{P} 4$ & 75 & Male & 3 months & Pulmonary clinic & Wife \\
\hline P5 & 70 & Female & 2,5 years & Pulmonary clinic & Child \\
\hline $\mathrm{P} 6$ & 70 & Male & 2,5 years & Pulmonary clinic & Wife \\
\hline $\mathrm{P} 7$ & 80 & Female & 1 year & In own home & Child \\
\hline $\mathrm{P} 8$ & 80 & Female & 1 year & Pulmonary clinic & Child \\
\hline P9 & 75 & Male & 1,5 years & In own home & Wife \\
\hline P10 & 70 & Female & 3 years & Pulmonary clinic & Child \\
\hline P11 & 75 & Male & 2,5 years & In own home & Wife \\
\hline $\mathrm{P} 12$ & 70 & Female & 2 years & Pulmonary clinic & Husband \\
\hline $\mathrm{P} 13$ & 65 & Female & 3 years & Pulmonary clinic & Husband \\
\hline
\end{tabular}

dying phase (Elkington et al., 2004; Sahlberg-Blom, 2001), and relatives are considered credible witnesses (Anderhed \& Ternestedt, 1998). The place for the interview was chosen by the relative (either their home or workplace), and each interview lasted between 25 and 80 minutes. An interview started with an open-ended question: "Can you please tell me about the last year of X's life?" After the preliminary questions, additional questions were asked about how COPD had affected the patient's daily life and if anything had been especially difficult, about their symptoms, about their contacts with healthcare services, and about the dying process and moment of death. The interviews were collected, audiotaped, and transcribed verbatim by the first author (KE).

To obtain a clearer and deeper picture of the illness's progression, relatives were asked to illustrate their experiences using a time axis as a complementary tool. This was done together with the interviewer. The time axis consisted of a line on which each month was marked, where the relative noted when the patient had been hospitalized as well as his or her periods of better or worse health. Notes were also made when new symptoms or other changes occurred concerning the patient's health and daily life. To aid their memory, seven of the relatives employed a diary or other notes made during the patient's illness when constructing the time axis. The interviews and the time axes were considered together for each patient.

\section{Analysis}

The interviews and time axes were analyzed separately. The analysis of the interviews was conducted first by means of content analysis (Graneheim \& Lundman, 2004). Thereafter, each time axis was analyzed with a focus on the illness's process and the patient's last year of life (see below).
Step 1. The interviews were read several times in order to obtain an overall impression of the content.

Step 2. Meaning units describing the patient's final year of life were identified and analyzed. The meaning units were condensed into comprehensive units and then coded. The codes that had something in common were combined into three subcategories (Table 2): (1) experiences of bodily losses, (2) periods of struggling between life and death, and (3) the unpredictability of death-which would later be compared with analysis of the time axes.

Step 3. The results of the analysis of the time axes showed recurring periods of severe exacerbations characterized by uncertainty about whether or not the patients would survive.

This was in line with two of the identified categories from the interviews. The analysis from both the interviews and time axes with a focus on the patient's last week of life showed two patterns: (1) a quick progression where the disease was characterized either by a temporary improvement for a short time before death, or (2) a slow disease progression with a gradual deterioration in the patient's condition.

Step 4. To critically verify the patterns that emerged from the analysis, the interviews were read again and compared with the time axes. The categories and subcategories identified in step 2 were confirmed. The categories were: (1) experiences of bodily losses, (2) periods of struggling between life and death, and (3) the unpredictability of death. The 
Table 2. Examples of content analysis from meaning units to category

\begin{tabular}{|c|c|c|c|c|}
\hline Meaning Units & Condensation & Code & Subcategory & Category \\
\hline $\begin{array}{l}\text { Sometimes her condition } \\
\text { deteriorated so quickly with } \\
\text { increasing breathing } \\
\text { difficulties when the only } \\
\text { thing to do was to rush }(. . .) \\
\text { there was no knowing } \\
\text { whether she would come } \\
\text { home again }\end{array}$ & $\begin{array}{l}\text { Rapidly increasing } \\
\text { breathing } \\
\text { difficulties }\end{array}$ & $\begin{array}{l}\text { Obvious } \\
\text { deterioration }\end{array}$ & $\begin{array}{l}\text { Periods of struggling } \\
\text { between life and } \\
\text { death }\end{array}$ & $\begin{array}{l}\text { Experiences of bodily } \\
\text { losses }\end{array}$ \\
\hline $\begin{array}{l}\text { He became confused from time } \\
\text { to time, which he experi- } \\
\text { enced as difficult (...) he } \\
\text { didn't recognize himself }\end{array}$ & $\begin{array}{l}\text { Was a stranger to } \\
\text { himself when he } \\
\text { was confused. }\end{array}$ & $\begin{array}{l}\text { Periods of } \\
\text { confused } \\
\text { self-image }\end{array}$ & $\begin{array}{l}\text { A challenged } \\
\text { self-image }\end{array}$ & \\
\hline $\begin{array}{l}\text { She had a peak a few days } \\
\text { before she died. At that time } \\
\text { she was very fit and walked } \\
\text { to the day room, so it was } \\
\text { very odd }\end{array}$ & $\begin{array}{l}\text { Suddenly gained } \\
\text { more energy and } \\
\text { was strong enough } \\
\text { to walk }\end{array}$ & $\begin{array}{l}\text { Temporary } \\
\text { improvement }\end{array}$ & $\begin{array}{l}\text { Temporary } \\
\text { improvement_death } \\
\text { was unexpected }\end{array}$ & $\begin{array}{l}\text { Living with } \\
\text { unpredictability of } \\
\text { death the last week } \\
\text { of life }\end{array}$ \\
\hline $\begin{array}{l}\text { Nothing much happened but } \\
\text { she just lay there and } \\
\text { somehow sank into a deep } \\
\text { sleep }\end{array}$ & $\begin{array}{l}\text { Became gradually } \\
\text { more tired and } \\
\text { slept for longer } \\
\text { periods }\end{array}$ & $\begin{array}{l}\text { Became slowly } \\
\text { weaker }\end{array}$ & $\begin{array}{l}\text { Continued } \\
\text { deterioration-death } \\
\text { was expected }\end{array}$ & \\
\hline
\end{tabular}

second category is based on the subcategories of "temporary improvement" (death is unexpected) and "continued deterioration" (death is expected).

Several strategies were employed to enhance the rigor of our findings. The first author (KE) carried out the interviews and analysis. During this process, time and space were provided for reflection, dialogue, and follow-up questions. The results and categories were also continuously discussed between the authors and in seminars together with other researchers from outside our research group.

\section{RESULTS}

According to relatives' stories, all the patients had the disease for between 10 and 15 years. The illness trajectory had a gradual and insidious deterioration-a state perceived as normal and relatively stable. This stable state was interrupted by shorter or longer bouts of deterioration. However, treatment often led to recovery and a new period of stability. Those periods usually created new hope in both patients and relatives during extended periods of improvement.

\section{Experiences of Bodily Losses}

When relatives compared the patient's health status during the final year of life to their previous health status, the differences consisted of increasingly stronger symptoms, more sudden deterioration, increased dependency, and significantly reduced quality of life, which affected their possibility for self-determination. This was particularly the case during periods of deterioration where dependence on other people increased. Relatives described it as the patient being forced to subordinate him/herself both in terms of their body and their possibilities for obtaining help and care. This limited their lives. According to relatives, the patients expressed that their body did not feel like before, that it had become dried up, or refused to obey them. Patients' struggles to cope with severe symptoms took on a new form. Such bodily symptoms as breathlessness, phlegm, coughing, and fungal infections of the mouth were described as especially difficult in terms of managing everyday life. Some patients also suffered from fever and swelling of the body. Phlegm was described as being a particularly difficult symptom with psychological, social, and existential effects. This can be exemplified by a son's story about his father, a man who made sure every day to dress well. The son explained that the father perceived the mucus to be the problem that he suffered from most because it made him feel undignified, which limited his everyday life:

I feel like a real slime, man. Every time I used to pass the old men on the bench in town who were coughing and spitting up phlegm, I always thought how disgusting they were. Now I'm one of them. 
A daughter described her mother's experiences in similar fashion:

She always had a carrier bag hanging next to her on the chair-folded paper so that she was prepared when she lacked the strength to cough [the phlegm] up. It was tough. She felt sickened by it and suffered on our behalf due to fear that we would find her disgusting.

The above quotations reveal that the sick person became nauseated due to their condition and that they feared being disgusting to others. The phlegm did not just affect the body-it also created existential reflection and affected the patients' self-image and perceptions of who they were.

The relatives' stories showed that those patients who had no close partner and lived alone were described as extra vulnerable, especially due to their dependency on others. These patients found it difficult to express their needs as well as to be strong enough to make their voice heard (e.g., when the breathing problems accelerated). Then they would withdraw and reduce their need for help or be quiet. A daughter described such a situation, telling how her mother felt violated when new staff came to help her prepare for bed without being aware of her needs and routines:

She was always at her best in the evening and did not go to bed before nine. But she became very tired at the end. She would lie on her bed with her clothes on because she didn't have the strength to take them off. (I usually helped the staff care for her at 9:00 o'clock in the evening; there was a silent agreement.) Then two [new care staff] came and started to undress her before seven, and it made her feel very small. She found it distressing, as she didn't know them.

The care staff helped this woman according to their routines and not on the basis of the woman's desires. In her vulnerable position, the woman lacked the strength to assert her will, and she felt violated and became frightened and silent. The attitude of the care staff had consequences both for the woman's self-image (she felt not respected as a person) and her sense of dignity. According to her daughter, the woman (her mother) was humbled.

According to relatives, confusion was a symptom that occurred often during the final year, but neither the patients nor relatives received any explanation or information about it. The level of confusion could change during the day and from one day to the next. The patients were sometimes clear, but shortly afterwards they became confused. The duration of such periods could be between one and several days. These periods of confusion constituted an additional threat to a patient's need for control and selfdetermination. The relatives described the fact that patients found it difficult to express themselves in the way they had been able to do before. One patient described herself as a "stranger to herself," explaining, "My brain is me, and this is not me," and "The body does what it wants and not what I want."

As described above, the attitude of the care staff toward a sick person could harm a patient's self-image and sense of dignity. The staff's attitude became an obstacle when they lacked understanding of the ill person's whole situation. Relatives reported that hospital care staff did not take patients' suffering seriously during such uncertain trajectories. The focus was on the physical symptoms, and psychosocial and existential needs were ignored.

\section{Struggling Between Life and Death}

As the disease progressed, obviously, the patients deteriorated. The view of the relatives at this time was that patients were undergoing a life-and-death struggle, especially when unexpected exacerbations often meant hospital care. Anxiety, irritation, and concern about the disease's development were clear. The relatives described how they often experienced these episodes as a time when the patients were dying and how they were repeatedly called to the hospital. On each occasion, they had said goodbye and prepared themselves for the person to soon pass away. Neither the physicians nor the nurses could predict whether or not patients would survive. The duration of these periods was described as varying between four days and one week. One daughter talked about her mother's disease as follows:

The shifts were very strong, and she was hospitalized many times. She could be fit in the morning, and then they would phone in the evening to say that I had better come because she hasn't got long to live, and it continued like that for a very long time.

Thus, the relatives also had to endure the struggle between life and death as regards their loved one. The daughter quoted above had gone through this cycle several times. It was described as stressful for her to repeatedly prepare for her mother's death. The relatives and patients had to constantly readapt when the disease took a new turn, and these rapid shifts between hope and despair were perceived as stressful.

Some patients had on those occasions talked about their impending death and how it would turn out. 
Relatives talked about how some patients had expressed fear and an expectation that their death would be painful and prolonged, just as their disease course had been. However, a common view was that patients avoided talking about dying or death, and when they recovered from a deterioration, they tried to return to normal life as soon as possible.

\section{Living with the Unpredictability of Death in the Last Week of Life}

Some 10 of the 13 patients were hospitalized for between two and six days before they died. The reason for hospitalization was a need for symptom relief, usually because the patient suffered from infections, and that the symptoms had become more severe. The other three were cared for in their homes and died there.

\section{Temporary Improvement: Death Is Unexpected}

Seven relatives reported that the patient showed a temporary improvement in his/her health status one to two weeks before their death. During this period, the patient's physical and mental energy increased, and such a marked improvement usually had not been seen during the past year. Some patients and relatives hoped that the disease had taken a turn for the better and that the patient's condition had improved. Care planning for discharge home was even discussed in some instances. The relatives of these patients described the death as "an event" that occurred suddenly and unexpectedly, even though they knew that the patient was seriously ill. One wife described it as follows:

We [wife and patient] had no idea that he might die. It just didn't occur to us. Instead, we thought he would become fit as usual and return home, because that is what had happened on previous occasions.

Since the patient and relatives had experienced uncertainty over a long period, varying patterns of the disease had become common, which perhaps made it more difficult to recognize changes in the patient's condition. The relative's descriptions also showed that the care staff were not aware that the patient was so close to death. It was only after the death that all involved realized that the patient's condition had deteriorated so quickly.

Some relatives had noticed that patients who had been experiencing frail health had been relatively strong during the final week of life. They took care of some practical issues, which may have indicated that the patients had had a premonition that life would soon end. For example, one man gave away important letters that he had gathered for his son. A woman who had been living in a difficult relationship decided to end it the week before she died. She wanted to die her own death and took the consequences of this decision. Of the seven patients who were reported to have experienced a temporary improvement in health, one patient spent the last week at home and died there. Five patients died in the presence of relatives, and their deaths were described as peaceful. The moment of death was described as unexpected and was characterized by a mild cough or sigh.

\section{Continued Deterioration: Death Is Expected}

Six relatives described the patient's dying as a continuous and ongoing deterioration of health. Nothing unexpected or sudden occurred during the final week of these patients' lives. The relatives noticed such physical signs as the patient's body becoming colder and gradually more cyanotic, which gave them an indication that death was near. The cyanosis had occasionally occurred during previous exacerbations but was now more obvious. The relatives described the death as expected. According to relatives, some patients had described a new feeling in their body or that they had lost their will to live shortly before their death-a feeling that they were going to die very soon.

One wife related the following about her husband's dying:

He had a new feeling in his body that he tried to describe to me: "It feels as if I will die soon," he said, and he slept all the time during the final days, and sometimes he looked up and asked if he was dead.

A husband reported the following:

It was strange because she said several times during the final week, "I will not live much longer."

Relatives reported that they had received explicit or implicit information from care staff members that the patient was dying and probably would not survive the present aggravation. One husband described how he interpreted the staff's attitude:

They came in a bit more often and checked on her, so it made you understand, even if they seemed uncertain if it was for real or definitive this time. [pause] They seemed more certain that time, I think.

Another husband got clear information about his wife's condition, and he put it this way:

The doctor came in and said that I should probably not count on her making it this time-that I should realize that it would soon be over. 
Although the dying trajectory was described as death being expected for these patients, the relatives had not noticed that something had changed that indicated the patient was dying. Patients gradually dropped into a deep sleep. Four died in the presence of their relatives and two without having any relatives beside them. From the relatives' perspective, death was not a nasty incident, but rather quite calm. The patients were described as looking like they were sleeping.

\section{DISCUSSION}

The aim of our study was to describe the final year of life of patients with advanced COPD based on reports by their relatives. Somewhat surprisingly, we found that all the relatives described how their relatives had a peaceful death, as opposed to the image they and the patient had most feared. Our results agree with previous studies showing that patients with advanced COPD are severely affected by both physical and psychosocial symptoms (Habraken et al., 2009; Blinderman et al., 2009; Walke et al., 2007; Jablonski et al., 2007; Elkington et al., 2005; 2004), often over a long period. The relatives in our study stated that the illness was uncertain, comprising severe exacerbations and an uncertain outcome. This meant that they felt that the patients could die every time they experienced an exacerbation. However, their health status often improved, and they continued to live. Previous studies have shown that patients and their relatives experience the exacerbations as an indication that death is drawing closer (Bailey Hill, 2001), and they that live in fear of future exacerbations (Gysels \& Higginson, 2010; Kessler et al., 2006; Heinzer et al., 2003). Characteristic of the final year of life in our study was that the patient's condition changed more rapidly than previously and that the symptoms intensified. This changing pattern created uncertainty regarding the severity of the patient's disease at the same time as the relatives lived with the hope that the patient would survive once again. This pattern is consistent with the experience that has been described by patients with severe heart failure, namely, life like a roller coaster (Brännström, 2007). The ambivalence of "living and dying" periodically created great uncertainty both for patients and their relatives (Brännström, 2007). In our study, the relatives described the emotionally difficult situation of having to say goodbye to each other over and over again and not knowing whether it was the final goodbye. That this was a strain for both the sick and their families was clear, but whether or not it was a source of stress is not demonstrated in the results.

Our results indicate two different dying patterns during the final week of life: one where the patient experiences a temporary improvement in health status and another characterized by continuous and ongoing deterioration before death occurs. It is not possible to establish whether or not these patterns are typical of those dying with COPD, as in this study we studied only the last year at an individual level. However, our results indicate that both the course of the disease and the death are unpredictable in patients with COPD. The seven patients in our study who experienced a temporary improvement during the final week were described as unusually fit, and discharge to home was being planned for some. Thus, the death of these patients were not presaged by obvious physical signs; life suddenly ended. Although the patient and his/her relatives were aware of the fact that life could end during the course of an exacerbation, they did not understand that the patient was dying when the patient actually died.

The question remains regarding at which stage the patient himself/herself realizes that he/she is dying. There are contradictory findings concerning patients' awareness about the trajectory of COPD and death. According to Cicutto and colleagues (2004), patients thought that they were in the final phase of the disease, whereas other studies demonstrated that the patients were not aware of the trajectory of the illness (e.g., Gardiner et al., 2009). Gardiner and coworkers (2009) found that patients with COPD fear suffocating to death and that the dying trajectory may be prolonged in the same way as the illness's trajectory is. A partly surprising result in our study was that all of our relatives described the patient as having had a peaceful death that did not correspond with the worry, for example, about suffocating to death, expressed by patients.

Our results indicated that the healthcare professionals did not pay attention to symptoms that could not be directly related to the lungs, such as patients' existential issues and worries, which could generate feelings of being marginalized. Several authors argue that this can be a consequence of the fact that healthcare professionals do not take psychosocial and existential needs into account and preferentially focus only on the physical aspects of COPD (Au et al., 2006; Skilbeck et al., 1998). An example in the present study is the daughter whose mother had recurrent periods of confusion. Despite the mother's difficult situation over a long period of time, the daughter had not had the opportunity to talk about dying from COPD (cf. Au et al., 2006; Hasson et al., 2008; Skilbeck et al., 1998). Thus, it is all the more important to be responsive to patients' existential needs and desire to talk about the end of life (Gysels \& Higginson, 2010).

Our results show that patients' final year of life involved extensive problems that affected their ability 
to participate in everyday life as they had before. With the help of Merleau-Ponty's (1997) thoughts on the "lived body," we can understand this further. A human not only has a body but also lives and creates meaning through the body (Merleau-Ponty, 1997). The lived body consists of the body-soulworld unit, and it is always related to a specific situation-for instance, the last week of life. We are involved in situations by being and living our body. Life perception, as well as access to the world, changes when the body changes. With COPD, a person experiences his/her own body changing over a long period of time. It is in the encounters with oneself and other people that the human becomes aware of his/her changing body-when the body begins to set limits. Living with COPD therefore becomes a special way of relating to life, and it also affects relatives' everyday lives. Interaction with the outside world affects both the person's perception of her/ himself and that of the disease. The relatives in our study described in particular how the phlegm and coughing contributed to the person's feelings of shame about their body. They felt disgusting and feared that others would perceive them as such. Relatives reported how the sick person's bodily changes also reduced the possibilities of being autonomous and that his/her self-image was negatively affected by the disease. The body behaved in a way that the patient had no control over. It could lead to patients withdrawing from social interaction and isolating themselves or becoming isolated. The bodily losses and dependence on others also had a strong existential meaning, especially in certain situations. The fact that the body, especially during severe episodes of the disease, also affects existential well-being is in line with the thoughts about the lived body formulated by Merleau-Ponty (1997). We not only have a body-we are our body. The body is the hub around which everything revolves.

This retrospective study was built upon relatives' experiences and memories of patients' life situations and dying during the final year of life. The interviews were conducted one to three years after the patient's death. Although the period between the patient's death and the interview may seem extended, the informants' descriptions were clear. Several of the relatives had kept a diary during the period of illness, and these were employed during the interviews, which strengthened their reliability. The relatives' way of talking about the now dead family member's last year of life indicated that they all remembered the process rather well regardless of whether they were partners, children, or siblings of the deceased. This information was particularly rich in content with respect to the final week of life, and it seemed that the time axis then served as a memory support and gave structure to the narrative. Our impression is that the relatives were credible witnesses. They talked about the family member's illness and death in a credible manner. Andershed and Ternestedt (1998) found that significant events that affect us often remain as detailed memories.

\section{CONCLUSION}

The patients and their relatives lived with uncertainty up until the time of death, which to a certain extent became a habit. During the last year, the situation deteriorated, and the patient suffered periods of unpredictable exacerbations with uncertain outcomes. The patient's practical and human needs increased, resulting in a high dependence on care. However, little support for his/her psychosocial and existential needs was available. It seems, therefore, essential for the nurse to create relationships with patients and relatives that enable them to talk about situations such as dying and death on their own terms. All patients experienced a peaceful death, contrary to what they and their relatives had expected. Death came in some cases after a period of substantial improvement. There is a need to prospectively follow patients with COPD during the last years of their life in order to further deepen our knowledge of the disease.

\section{REFERENCES}

Andershed, B. \& Ternestedt, B.M. (1998). The illness trajectory for patients with cancer who died in two different cultures of care. OMEGA Journal of Death and Dying, $37,251-272$.

Au, D.H., Udris, E.M., Fihn, S.D., et al. (2006). Differences in health care utilization at the end of life among patients with chronic obstructive pulmonary disease and patients with lung cancer. Archives of Internal Medicine, 166, 326-331.

Bailey Hill, P. (2001). Death stories: Acute exacerbations of chronic obstructive pulmonary disease. Qualitative Health Research, 11, 322-338.

Barnett, M. (2005). Chronic obstructive pulmonary disease: A phenomenological study of patients' experiences. Journal of Clinical Nursing, 14, 805-812.

Blinderman, C.D., Homel, P., Billings, A., et al. (2009). Symptoms, distress and quality of life in patients with advanced chronic obstructive pulmonary disease. Journal of Pain and Symptom Management, 38, 115-123.

Brännström, M. (2007). A life in a roller-coaster: Meanings of living with severe heart-failure in palliative care home care based on patients, next-of-kin and nurses stories. Doctoral dissertation. Umeå University, Umeå, Sweden.

Cicutto, C.A., Brooks, D. \& Henderson, K. (2004). Self-care issues from the perspective of individuals with chronic obstructive pulmonary disease. Patient Education and Counseling, 55, 168-176. 
Claessens, M.T., Lynn, J., Zhong, Z., et al. (2000). Dying with lung cancer or chronic obstructive pulmonary disease: Insight from SUPPORT-Study to understand prognoses and preferences for outcomes and risk treatments. Journal of the American Geriatrics Society, 48, 146-153.

Curtis, J.R., Marjorie, D., Wenrich, J.D., et al. (2002). Patients' perspective on physician skills in end-of-life care: Differences between patients with COPD, cancer, and AIDS. Chest, 122, 356-362.

Edmonds, P., Karlsen, S., Khan, S., et al. (2001). A comparison of the palliative care needs of patients dying from chronic obstructive disease and lung cancer. Palliative Medicine, 15, 287-295.

Ek, K. (2010). Living with very severe chronic obstructive pulmonary disease: A life in slow motion. Doctoral dissertation. Orebro University; Örebro, Sweden.

Ek, K. \& Ternestedt, B.M. (2008). Living with chronic obstructive pulmonary disease at the end of life: A phenomenological study. Journal of Advanced Nursing, $62,470-478$.

Ek, K., Andershed, B., Sahlberg-Blom, E. \& Ternestedt, B.M. (2011a). Struggling to retain living space: Patients' stories about living with advanced chronic obstructive pulmonary disease. Journal of Advanced Nursing, 67(79), 1480-1490.

Ek, K., Ternestedt, B.M., Andershed, B. \& Sahlberg-Blom, E. (2011b). Shifting life rhythms: Couples stories about living together when one partner has advanced chronic obstructive pulmonary disease. Journal of Palliative Care, 27(3), 189-197.

Elkington, H., White, P., Addington-Hall, J., et al. (2004). The last year of life of COPD: A qualitative study of symptoms and services. Respiratory Medicine, 98, $439-445$.

Elkington, H., White, P., Addington-Hall, J., et al. (2005). The health care needs of chronic obstructive pulmonary disease patients in the last year of life. Palliative Medicine, 19, 485-491.

Fraser, D.D., Kee, C.C. \& Minick, P. (2006). Living with chronic obstructive pulmonary disease: Insiders' perspectives. Journal of Advanced Nursing, 55, 550-558.

Gardiner, C., Gott, M., Small, N., et al. (2009). Living with advanced chronic obstructive pulmonary disease: $\mathrm{Pa}-$ tients concerns regarding death and dying. Palliative Medicine, 23, 691-697.

Gott, M., Gardiner, N., Small, S., et al. (2009). Barriers to advance care planning in chronic obstructive pulmonary disease. Palliative Medicine, 23, 642-648.

Graneheim, U.H. \& Lundman, B. (2004). Qualitative content analysis in nursing research: Concept, procedures and measures to achieve trustworthiness. Nurse Education Today, 24, 105-112.

Gullick, J. \& Stainton, C. (2008). Living with chronic obstructive pulmonary disease: Developing conscious body management in a shrinking life-world. Journal of Advanced Nursing, 64, 605-614.

Gysels, M. \& Higginson, I.J. (2010). The experience of breathlessness: The social course of chronic obstructive pulmonary disease. Journal of Pain and Symptom Management, 39, 555-563.

Habraken, J.M., Willems, D.L., de Kort, S.J., et al. (2007). Health care needs in end-stage COPD: A structured literature review. Patient Education and Counseling, 68, $121-130$.

Habraken, J.M., ter Riet, G., Gore, J.M., et al. (2009). Health-related quality of life in end-stage COPD and lung cancer patients. Journal of Pain and Symptom Management, 37, 973-981.

Hall, S., Legault, A. \& Cotè, J. (2010). Dying means suffocating: Perceptions of people living with severe COPD facing the end of life. International Journal of Palliative Nursing, 16(9), 451-457.

Hasson, F., Spence, A., Waldron, M., et al. (2008). I can not get a breath: Experiences of living with advanced chronic obstructive pulmonary disease. International Journal of Palliative Nursing, 14, 527-531.

Heinzer, M.M.V., Bish, C. \& Detwiler, R. (2003). Acute dyspnoea as perceived by patients with chronic obstructive pulmonary disease. Clinical Nursing Research, 12, 85-101.

Jablonski, A., Gift, A. \& Cook, K.E. (2007). Symptom assessment of patients with chronic obstructive pulmonary disease. Western Journal of Nursing Research, $29,845-863$.

Jones, I., Kirby, A., Ormiston, P., et al. (2004). The needs of patients dying of chronic obstructive pulmonary disease in the community. Family Practice, 21, 310-313.

Kessler, R., Ståhl, E., Vogelmeier, C., et al. (2006). Patient understanding, detection and experience of COPD exacerbations. Chest, 130, 133-142.

Lowey, E.S., Norton, A.S., Quinn, R.J., et al. (2013). Living with advanced heart failure or COPD: Experiences and goals of individuals nearing end of life. Research in Nursing \& Health, 36, 349-358.

Lunney, J.R., Lynn, J., Foley, D.J., et al. (2003). Patterns of functional decline at the end of life. The Journal of the American Medical Association, 18, 2387-2392.

Lynn, J., Ely, W., Zhong, Z., et al. (2000). Living and dying with chronic obstructive pulmonary disease. Journal of the American Geriatrics Society, 48, 91-100.

Maurer, J., Rebbapragada, V., Borson, S., et al. (2008). Anxiety and depression in COPD. Chest, 134, 43-56.

Melin-Johansson, C., Ödling, G., Axelsson, B., et al. (2008). The meaning of quality of life: Narrations by patients with incurable cancer in palliative home care. Palliative \& Supportive Care, 6, 231-238.

Merleau-Ponty, M. (1997). Kroppens fenomenologi [The phenomenology of perception]. Göteborg, Sweden: Daidalos AB.

Murray, S.A., Kendall, M., Boyd, K., et al. (2005). Illness trajectories and palliative care. British Medical Journal, 330, 1007-1011.

Nguyen, M., Chamber-Evans, J., Joubert, A., et al. (2013). Exploring the advance care planning needs of moderately to severely ill people with COPD. International Journal of Palliative Nursing, 19(8), 389-395.

Patton, M. (2002). Qualitative research and evaluation methods, 3rd ed. London: Sage Publications.

Rabe, K.F., Hurd, S., Anzueto, A., et al. (2007). Global strategy for the diagnosis, management, and prevention of chronic obstructive pulmonary disease: Gold executive summary. American Journal of Respiratory and Critical Care Medicine, 176, 532-555.

Reinke, L.F., Engelberg, R.A., Shannon, S.E., et al. (2008). Transition regarding palliative and end-of-life care in severe chronic obstructive pulmonary disease or advanced cancer: Themes identified by patients, families and clinicians. Journal of Palliative Medicine, 11, 601-609.

Sahlberg-Blom, E. (2001). Autonomy, dependency, and quality of life: The last month of life for 56 cancer patients. Doctoral dissertation. Uppsala, Sweden: Uppsala University. 
Seamark, D.A., Blake, S.D., Seamark, C.J., et al. (2004). Living with severe chronic obstructive pulmonary disease (COPD): Perceptions of patients and their carers-an interpretative phenomenological analysis. Palliative Medicine, 18, 619-625.

Seymour, J. \& Ingleton, C. (2004). Transition into the terminal phase: Overview. In Palliative care nursing principles and evidence for practice. S. Payne, J. Seymour \& C. Ingleton (eds.), pp. 189-217. Maidenhead, Berkshire: Open University Press.

Shackell, B.S., Jones, R.C., Harding, G., et al. (2007). “Am I going to see the next morning?" A qualitative study of patients' perspectives of sleep in COPD. Primary Care Respiratory Journal, 16, 378-383.

Skilbeck, J., Mott, L., Page, D., et al. (1998). Palliative care in chronic obstructive pulmonary disease: A needs assessment. Palliative Medicine, 12, 245-254.

Spence, A., Hasson, F., Waldron, M., et al. (2009). Professionals delivering palliative care to people with COPD: Qualitative study. Palliative Medicine, 23, $126-131$.
Strang, S., Ekberg-Jansson, A., Strang, P., et al. (2013). Palliative care in COPD: A web survey in Sweden highlights the current situation for a vulnerably group of patients. Uppsala Journal of Medical Sciences, 118(3), $181-186$.

van Manen, J.G., Bindels, P.J.E., Dekker, F.W., et al. (2002). Risk of depression in patients with chronic obstructive pulmonary disease and its determinants. Thorax, 57, $412-416$.

Wagena, E.J., Arrindell, W.A., Wouters, E.F.M., et al. (2005). Are patients with COPD psychologically distressed? European Respiratory Journal, 26, 242-248.

Walke, L.M., Byers, A.L., Tinetti, M.E., et al. (2007). Range and severity of symptoms over time among older adults with chronic obstructive pulmonary disease and heart failure. Archives of Internal Medicine, 167, 2503-2508.

Werkander-Harstäde, C. (2012). Guilt and shame in endof-life care: The next-of-kin's perspective. Doctoral dissertation. Växsjö, Sweden: Linnaeus University.

World Health Organization (2007). Chronic respiratory disease (COPD): Burden. Geneva: WHO. 